\title{
Impacts of Human Activities on the Generating Capacity of Negative Air Ions in Different Functional Areas of Hefei, China
}

\author{
Fengling Zeng ${ }^{1}$, Tiancheng Zhang ${ }^{1}$, Ze Wu ${ }^{1}$, Shuyun Yang ${ }^{1,2}$, \\ Zhiqing Cheng ${ }^{1}$, Fengwen Wang ${ }^{1 *}$ \\ ${ }^{1}$ College of Resources and Environment, Anhui Agricultural University, Hefei 230036, China \\ ${ }^{2}$ Hefei Agricultural Environment Science Observation and Experiment Station, Ministry of Agriculture, \\ Hefei 230036, China
}

Received: 31 May 2021

Accepted: 9 October 2021

\begin{abstract}
In order to determine the generating capacity of negative air ions (NAIs) and its relationship with human activities, the NAIs in different functional areas of Hefei, China, were analyzed. And the half residence time was studied by simulated experiments. The results showed that the natural attenuation law of NAIs was complied with this equation: $C_{(t)}=2986.6 \times e^{-0.0141 t}$. Based on the attenuation equation, the coagulation rate $\alpha=0.0141$, and the lifespan was about $49.16 \mathrm{~min}$. Combined with the NAIs concentration monitored in different functional areas, it was found that there was a huge difference in background concentration and environmental production or consumption. The background concentration in urban forest area was much higher, indicating that plants were the main source of NAIs. Among them, the urban forest area (UF), water area (WA), culture and education area (CEA) and residential area (RA) produced NAIs, while others consumed. There was a threshold value for the consumption by human activities, which was generally no more than $30 \%$ and can reach $50 \%$ when the activity was intense. However, no threshold value was found for vehicle activities. These results can provide reference for other mid-latitude inland cities to optimize urban design, and build 'resilient cities'.
\end{abstract}

Keywords: NAIs, half residence time, human activities

\section{Introduction}

China's rapid urbanization over the past four decades has proved that cities make life better. However, due to its siphon and spillover effect,

*e-mail: 1922146451@qq.com the continuously improved level of urbanization attracts a large number of population and industrial enterprises to flood into cities, which makes the process of urban development speed up while also accumulating a large number of ecological and environmental problems. It means there is a significant negative spatial correlation between population urbanization and the total value of ecosystem services [1]. 'Urban disease' has become an obvious shortcoming of China's social development. 
Covid-19, which broke out in late 2019 and continues to this day, has sparked a new wave of interest in the health industry, while people pay more attention to improving their own immunity [2]. Therefore, it is of great significance to discuss the impact of air pollution on the quality of urbanization and to think about how to achieve the win-win strategic goal of social economy and ecological environment.

Hefei, the capital of Anhui Province, China, is located in the west of the Yangtze River Delta. It has four distinctive seasons, mild climate and moderate rainfall, which makes Hefei a representative city in the middle latitudes with the most obvious subtropical monsoon humid climate. In addition, the development of Hefei in recent years also has its typicality and representative. It develops rapidly under the fierce competition of Zhengzhou, Wuhan and other provincial capitals in central China. Hefei has grown from a population of 800,000 , ranking about $70^{\text {th }}$ in the $1980 \mathrm{~s}$, to the current population of 5 million, ranking about $20^{\text {th }}$. In these four decades, Economic growth rate of Hefei ranks first in the whole country. Therefore, studying urban air quality improvement in connection with the economic development of Hefei can provide reference for other mid-latitude cities to realize the two-step approach of 'city height (high-quality development)' and 'city temperature (high-quality life)'and to build a 'resilient city'.

The ability to produce NAIs, which are regarded as 'Blue Vitamin', becomes the first measurement of air quality in the region [3-4]. Due to the extremely important significance of air anion in environmental hygiene, biology and medicine [5-7]. The domestic and foreign scholars have conducted a series of studies on it. Vana M. studied the concentration of environmental negative ions on the west coast of Ireland [8]. Zhang F.J. summarized the diurnal and seasonal variation rules of air negative ion concentration in Xiamen [9-10]. Chen B.F. and Tao X.Y. discussed the influence of environmental factors on air anions [11-12]. However, most of the studies focus on the change law of anions and environmental effects, and few involve the quantitative model of environmental production or consumption of anions let alone the influence of human activities on it.

\section{Experimental}

\section{Setting of Observing Point}

In this study, the urban area of Hefei was divided into 7 functional areas, cultural and educational area (CEA), commercial area (CA), residential area (RA), industrial and mining area (IMA), water area (WA), traffic area (TA) and urban forest area (UFA). Among them, the measure points of CEA were located on the road, the platanus forest and the greenbelt in front of the first teaching building of Anhui Agricultural University (AAU). The measuring points of CA was set in Hefei City Hall Square. The 3 measuring points of RA were set in the international student apartment of $\mathrm{AAU}$, greenbelt and residence in Amber Villa. The measuring point of IMA was located in the factory area of Hefei Steel Company. The representatives of WA were placed in Dongpu Reservoir and Heichi Dam. The observation posts of UFA were set in cedar, poplar and bamboo in Dashu Mountain Forest Park. The observing points of TA were located in the intersection of Sanxiaokou, Changjiang Road, and the south gate of AAU. The distribution of each monitoring point is shown in Fig. 1.

The experiment of natural attenuation of NAIs was carried out in the meteorology laboratory of AAU.

\section{Measured Contents and Equipment}

The concentration of NAIs was measured by AIC1000 air ion tester (AIC, USA). The detection range of this type of air ion detector is $10 \sim 1.999 \times 10^{6}$ per $\mathrm{cm}^{3}$.

From January 1 to December 31, 2019, the concentration of NAIs at the representative monitoring points in different functional areas of Hefei was measured every sunny day from 6 a.m. to 18 p.m. for an hourly interval

The natural attenuation experiment of negative air ion was simulated by negative air ion generator (M-Y50, Moral, Germany), and the axial wind speed of the negative air ion generator was measured by the electronic hot-bulb breeze meter (EY3-2A, AC, China).

Fig. 2 shows an artificially simulated anion generation environment. The negative ion generator was arranged in a closed room of $3 \times 3 \times 2.7$ (unit: $m$ ). The air anion detector was placed along the axis of the outlet of the anion generator at $1.1 \mathrm{~m}$, which was used to monitor the natural attenuation of anions. We turned the anion generator on for 12 hours and then turned it off. The readings of the air anion detector were taken every 3 minutes.

\section{Calculating Method}

The disappearance of anions in air is mainly due to the neutralization of charge generated by random collisions. The neutralization amount per unit time is determined by the concentration of negative ions and the probability of collision [13]. Assume that $C_{(0)}$ is the concentration of NAIs at the initial moment, $C_{(t)}$ is the concentration of NAIs at any moment, $d C_{(t)}$ is the neutralization amount caused by random collision, and $\alpha$ is the collision probability, then $\alpha$ can calculated as follows:

$$
\alpha=\frac{d C_{(t)}}{C_{(t)}}
$$




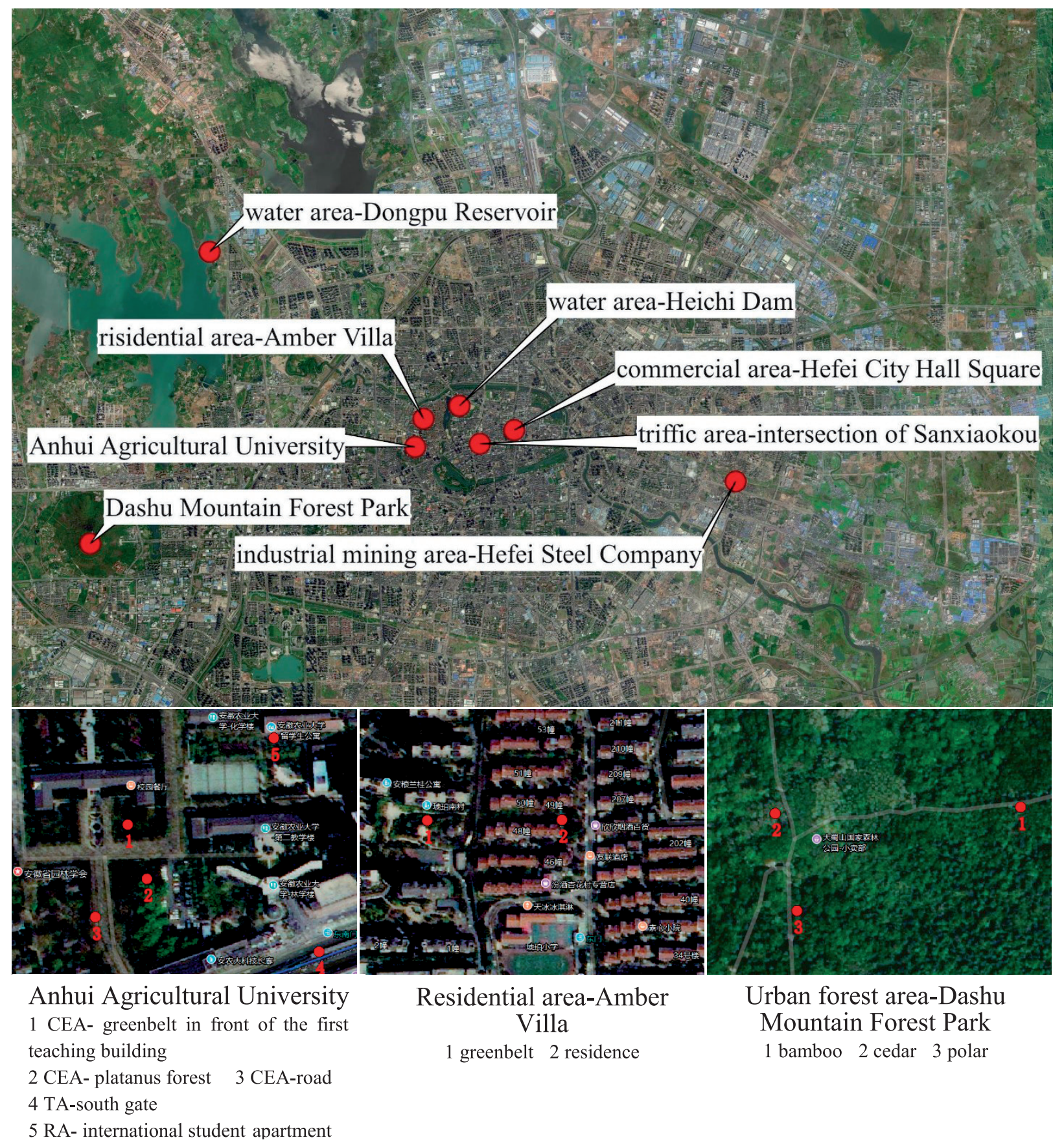

Fig. 1. The distribution of monitoring points in Hefei City.
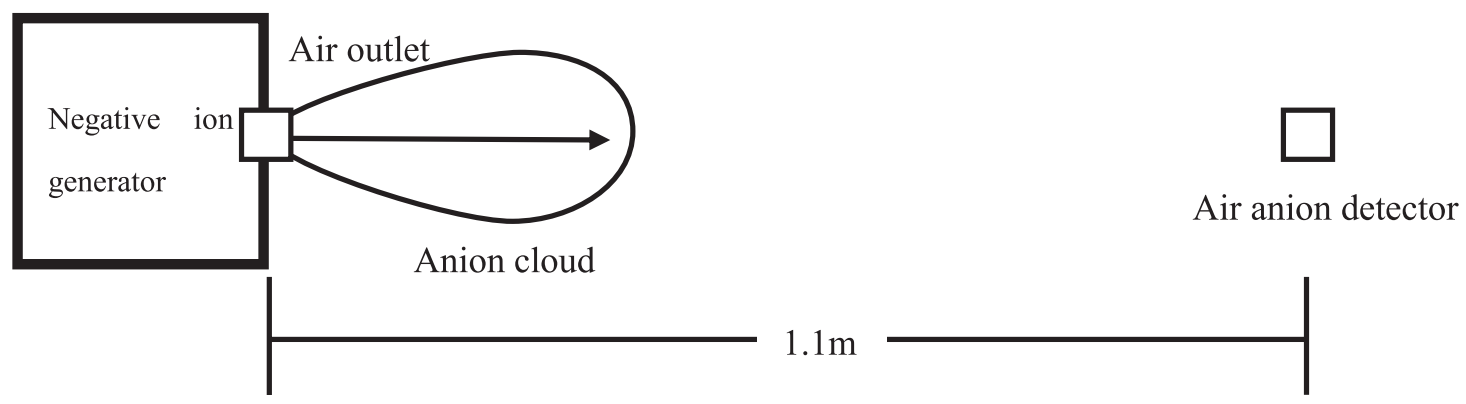

Fig. 2. Apparatus distribution and anion cloud. 
Integrating the above equation, we can get the concentration of anion in air at any time:

$$
C_{(t)}=C_{(0)} \times e^{-\alpha t}
$$

By artificial simulation, the negative ion concentration can reach a certain level. Then let them attenuate without interference. $\alpha$ can be estimated by fitting time and negative ion concentration.

Since the NAIs attenuate according to the negative exponential model, the time required to reduce its concentration to half of the initial concentration is the half residence time, which is expressed as:

$$
T_{\frac{1}{2}}=-\frac{1}{\alpha} \ln \frac{1}{2}
$$

The background concentration in different functional areas of Hefei can be estimated by the average value of data which observed at 6 a.m. Then we can get the quantity of NAIs in the atmosphere per $\mathrm{cm}^{3}$, which the environment provides or consumes on the hour, that equals the differences between hourly and background concentration divides by the half residence time. Therefore, the total quantity provided by the environment in different functional areas can be estimated as follows:

$$
Q=\sum_{i=6}^{17} \frac{\left(q_{i}+q_{i+1}\right)}{2} \times 60
$$

$Q$ is the total amount of negative ions produced or consumed from 6 a.m. to 18 p.m. And $q_{i}, q_{i+1} \ldots$ are the quantity of negative ions produced or consumed at each hour.

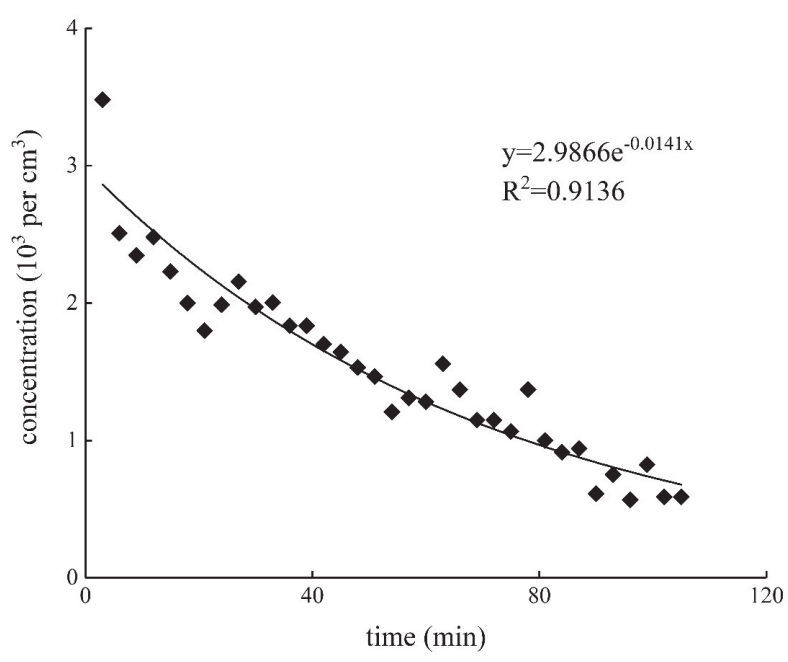

Fig. 3. Simulation of the natural attenuation of anion.

\section{Results and Discussion}

According to the experimental data, we can get some characteristics about the change of NAIs concentration of Hefei. For example, the concentration of NAIs in the UFA of Hefei is much higher than that in other urban functional areas, and it has the functions of physiotherapy and recuperation. The air in CEA, RA and WA can be considered clean. But in CA, TA, IMA, the air cleanliness valuation is bad which means air pollution is serious. The concentration of anion in air is closely related to the photosynthesis of plants. These results are in accordance with some previous research of other scholars [14-17]. Based on the above background, this paper focused on studying the negative ions produced or consumed in different environments in Hefei and the influence of human activities on the concentration of negative ions in the air.

\section{The Half Residence Time}

Fig. 3 is fitted with the data obtained from the artificial natural attenuation experiment, and the negative ion concentration equation corresponding to this process is estimated as:

$$
C_{(t)}=2986.6 \times e^{-0.0141 t}
$$

It means $\alpha=0.0141$. Then we can get $T_{\frac{1}{2}}=49.16 \mathrm{~min}$.

\section{Background Concentration and Environmental} Production in Different Functional Areas

Fig. 4 shows the distribution of NAIs background concentration in different functional areas of Hefei City based on the data at 6 a.m. Fig. 5 shows the number of anions generated or consumed in different functional areas by using the half residence time of air anions of 49.16 minutes and equation (4). It can be seen that there are great differences in the background concentration of NAIs among different functional areas. The background concentration of UFA with recuperated function is about 867 per $\mathrm{cm}^{3}$, and the daily total

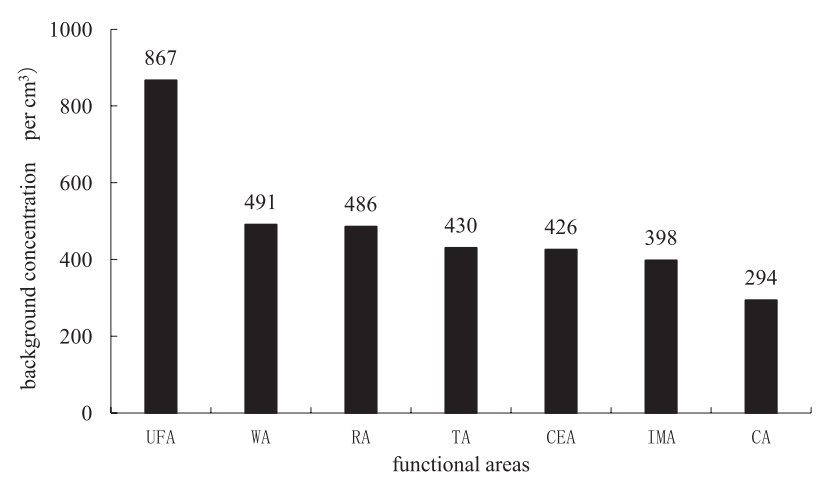

Fig. 4. The distribution of negative air ions background concentration in different areas of Hefei. 


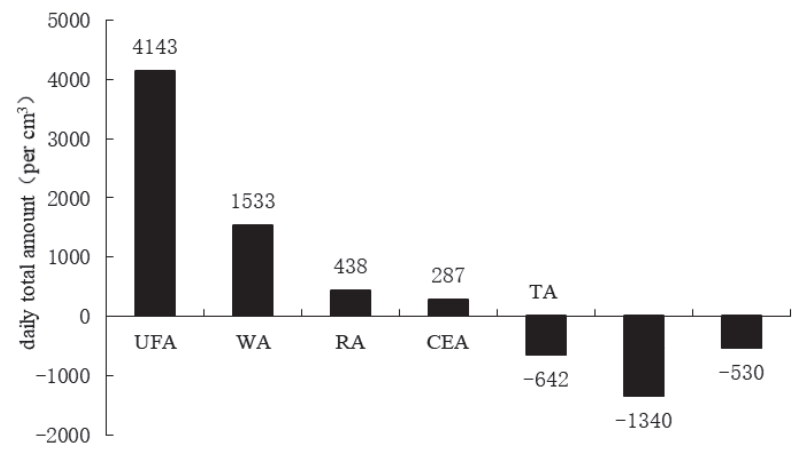

Fig. 5. Daily total amount of negative air ions produced or consumed by different functional areas in Hefei.

amount can reach 4143 per $\mathrm{cm}^{3}$. It is much higher than other functional areas, showing the strong function of urban forest in improving urban living environment. And the performance of the WA can't be ignored. It also net products NAIs 1533 per $\mathrm{cm}^{3}$. The main reason is that water droplets break up as they move. When they break up, they lose electrons to become positive ions. The surrounding air traps these electrons to become negative ions. [18] Because of the high greening rate, the RA and the CEA have stable greening ecological effect. Although the background NAIs concentration is low, the environment composed of artificial green vegetation can still yield a net production. The daily total amounts are 438 per $\mathrm{cm}^{3}$ and 287 per $\mathrm{cm}^{3}$. However, in the TA, the IMA and the CA, there are not only low background concentration, but the environment also consumes NAIs. In particular, the consumption of negative ions in IMA is the largest, with a net daily consumption of 1340 ions per $\mathrm{cm}^{3}$.

\section{The Consumption by People Activities}

Through calculation and comparison of the measured data, it was found that the change

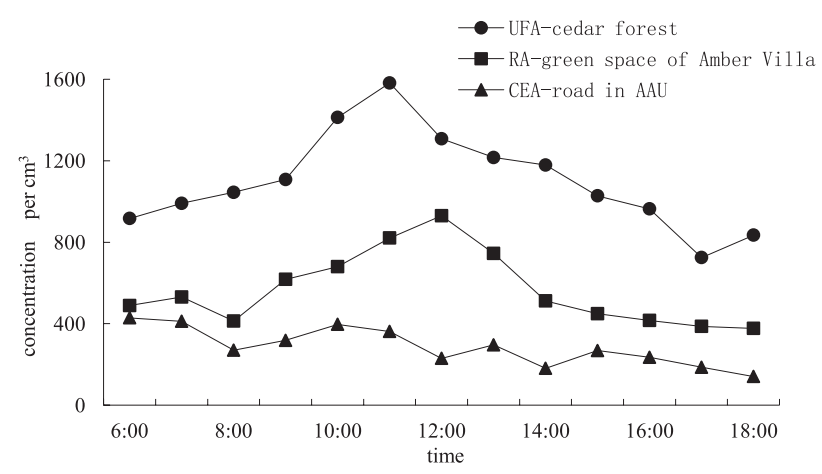

Fig. 7. Diurnal variation of negative ion concentration in cedar forest, green space of Amber Villa and road in AAU.

of negative ion concentration at the cedar forest in Dashu Mountain Forest Park had the most significant relationship with time, so this measuring point was taken as the control. The air anion concentration per hour was divided by the background concentration of UFA to obtain the relative value distribution of the daily diurnal variation of anion concentration in the cedar forest of Dashu Mountain Forest Park that is showed in Fig. 6. The concentration of negative ions in the cedar forest is very high throughout the day that shows a kind of unimodal variation, and the maximum value appears around 11 a.m. Human activities in CEA and RA mainly include walking, sports and daily life.

Through data comparison, it is found that the relationship between the concentration of negative ions in the air and the intensity of human activities is most significant in the road of AAU and the green space of Amber Villa. Therefore, these two measuring points are taken as representatives in this paper to analyze the influence of people activities on negative ions.

As can be seen from Fig. 7, the characteristics of the concentration in green space of Amber Villa are similar to those in the cedar forest. It is also unimodal

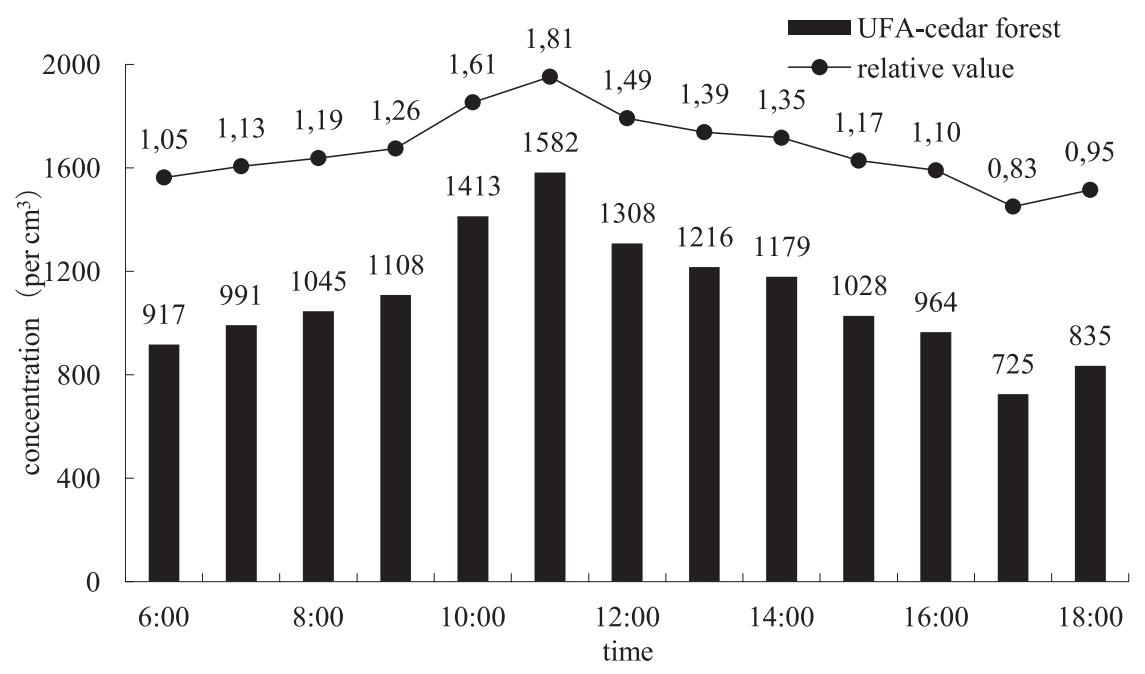

Fig. 6. The relative value distribution of the diurnal variation of anion concentration in the cedar forest in Dashu Mountain Forest Park. 
variation, but the concentration at 8 a.m. is slightly lower. The maximum value appears at 12 a.m. and that appears at 11 a.m. is the second largest value. Based on the analysis of the activity characteristics of the residents of Amber Villa, the low value at 8 a.m. is due to the fact that the residents go to work in large numbers, and the personnel activities are intense, so that the consumption of negative ions is greater than the amount of environmental production. Similarly, around 11 a.m., children come home after school and adults get off work which caused certain disturbance to the green space. Although the intensity is lower than that in the morning, the concentration of negative ions decreased, leading to the delay of the peak value. However, around 12 a.m., residents basically have lunch and rest at home, and the disturbance effect of personnel activities on the green space is at a minimum. The negative ions generated by the environment are greater than the consumption and accumulated, so the peak value of the whole day appears.

Compared with UFA and RA, the diurnal variation characteristics of negative ions concentration in CEA are more complex with multiple maximum and minimum values, which are basically inversely correlated with the frequency of human activities. The concentration of negative ions at the measuring point in road of AAU in the CEA reaches its absolute maximum value around 6 a.m., and then begins to decline, with three relative minimum values appearing at 8 a.m., 12 a.m. and 14 p.m. And three relative maximum are showed at 10 a.m., 13 p.m. and 15 p.m. The minimum value at 8 a.m. is 270 per $\mathrm{cm}^{3}$, and it decreases to 230 per $\mathrm{cm}^{3}$ at 12 a.m., then it further decreases to 181 per $\mathrm{cm}^{3}$ at 14 p.m. The peak that should have appeared at 11 a.m. only appears a maximum slightly lower than the morning peak at 10 a.m., and then the extreme values go down all the way.

Based on the relative value distribution of negative ions concentration of cedar forest in the UFA that is shown in Fig. 6, the simulated value of negative ion in the road in AAU was obtained in Fig. 8. Compared with the measured values, the simulated values at 6 a.m. and 7 a.m. are lower than the measured values. For the rest, they are higher than the measured values to varying degrees. The difference between the simulated values and the measured values can be considered as the 'consumption' of NAIs by human activities. At different time, due to the different intensity of personnel activities, negative ions in the air are consumed to different degrees. There are three negative ions consumption peaks on campus all day, which are at 12 a.m., 14 p.m. and 18 p.m. And the consumption of negative ions is about 196 per $\mathrm{cm}^{3}, 203$ per $\mathrm{cm}^{3}$ and 131 per $\mathrm{cm}^{3}$, respectively. The consumption of anion at 12 a.m., 14 p.m. and 18 p.m. when the human activities are the most intense, can reach $45.95 \%, 52.81 \%$ and $48.10 \%$ respectively. Other periods do not exceed $30.00 \%$ generally. By using the flows of people and the corresponding NAIs concentration at different time in the CEA, the relationship between the concentration of negative ions and the flows of people per minute is fitted as follows: $y=417.20-$ $0.56 \mathrm{x}$.

The above analytical results show that simple human activities such as walking, visiting a garden consume negative ions certainly. The consumption accounts for about $28.50 \%$. Only when the flows of people are extremely serious, it can be more than $50.00 \%$. Therefore, in order to guarantee the recuperative capacity, it is needed to control the flows of people.

\section{The Consumption by Vehicles}

Fig. 9 shows the variation of average daily negative ion concentration at Sanxiaokou. Sanxiaokou in TA belongs to the most congested Changjiang Road in Hefei, and its main active body is the vehicle passing at high speed. Therefore, the data in Sanxiaokou

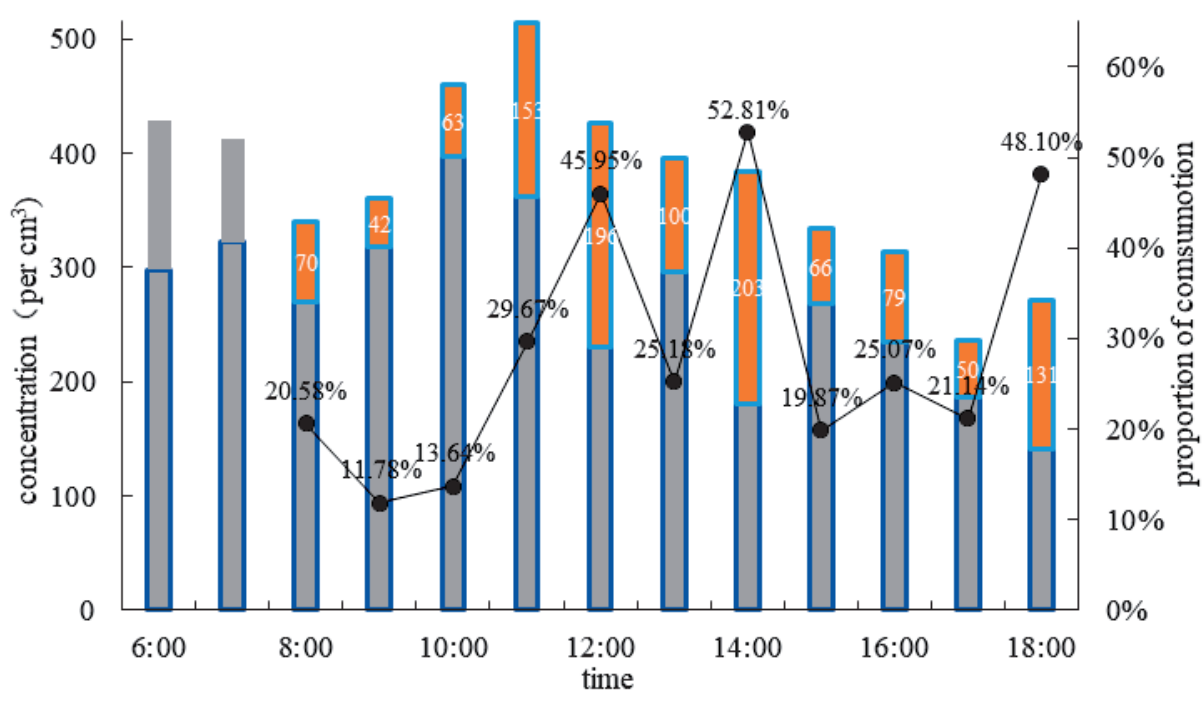

Fig. 8. The measured values, simulated values and proportion of consumption of negative air ions in the road of AAU. 


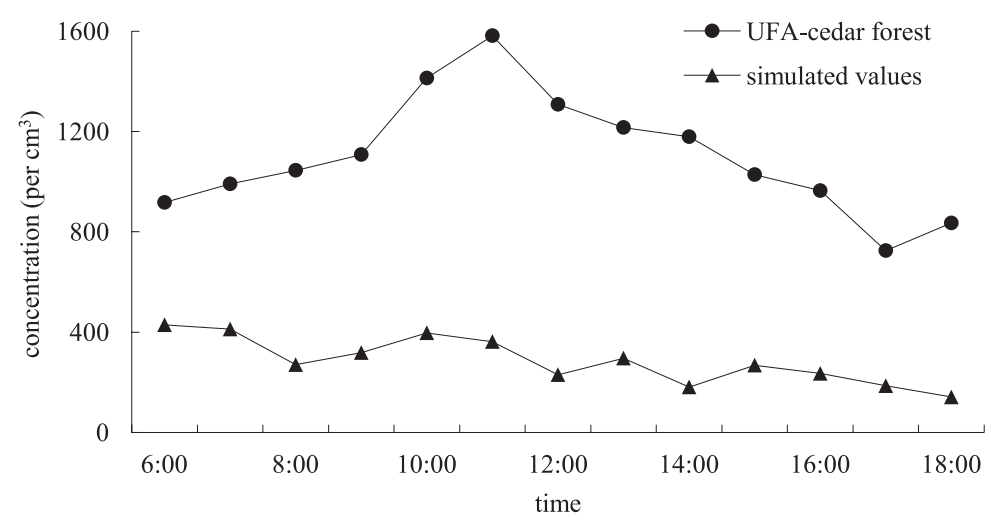

Fig. 9. Diurnal variation of negative ion concentration in cedar forest and Sanxiaokou.

is used to analyze the consumption of NAIs by vehicles. The level of anion in the air at the Sanxiaokou is equivalent to that in the CEA and RA in the morning, however because the transport gets exhilarating from 8 a.m, the concentration decreases rapidly, and it almost shows a unilateral downward trend except for a slight increase in the time when the vehicle activity is relatively less. the relationship between the concentration of negative ions and the vehicle flows per 5 minutes is fitted as follows: $y=471.26-0.35 x$.

As same as the above method, the simulated value of negative ion concentration in at Sanxiaokou and the proportion of consumption are estimated on the basis of the relative value of negative ion concentration in cedar forest in Dashu Mountain Forest Park (Fig. 10). The consumption ratio reaches the highest values of $83.85 \%, 87.84 \%$ and $90.40 \%$, at 11 a.m., 14 p.m. and 18 p.m., respectively. It is consistent with the residents' commuting peak, and far exceeds the CEA and RA. This indicates that the disturbance of vehicle activity to air anions is much stronger than that of people activity, and can quickly consume most of the anions in the air in a short time.

\section{The Consumption by Mixing People and Vehicles}

There is a jumble of people and cars in CA, and the speed is as slow as walking. Therefore, it is possible to measure the consumption of NAIs by mixing people and vehicles. As shown in Fig. 11, the variation of the daily average negative ion concentration at the measurement point of City Hall Square can be seen, the concentration of anion remains low throughout the day, peaking at 6 a.m. and then decreasing monotonously.

Fig. 12 shows the simulated value and consumption ratio of the concentration of negative ions in air of City Hall Square. After 8 a.m., the consumption of anion in the air of the City Hall Square is similar to that of Sanxiaokou, which maintains at a very high level all day, reaching more than $50.00 \%$. It indicates that

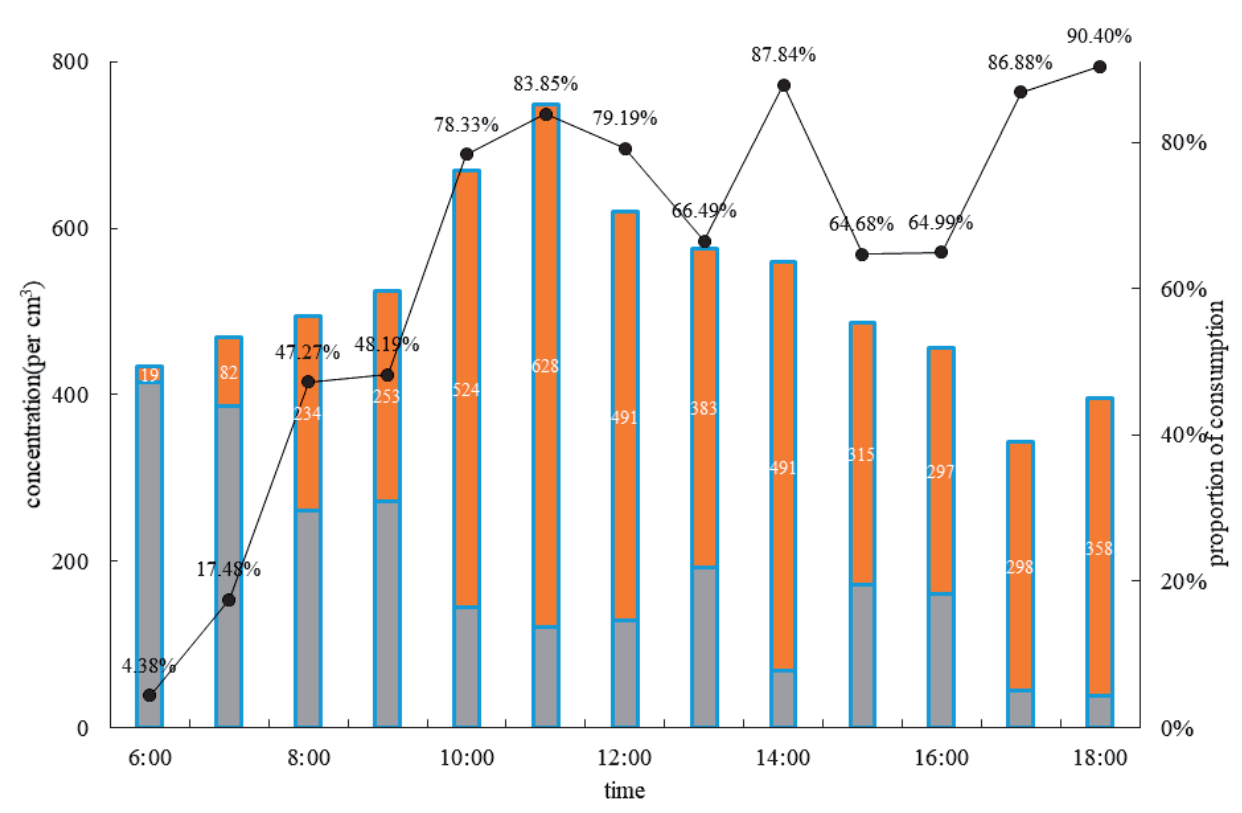

Fig. 10. The measured values, simulated values and proportion of consumption of negative air ions in the intersection of Sanxiaokou. 


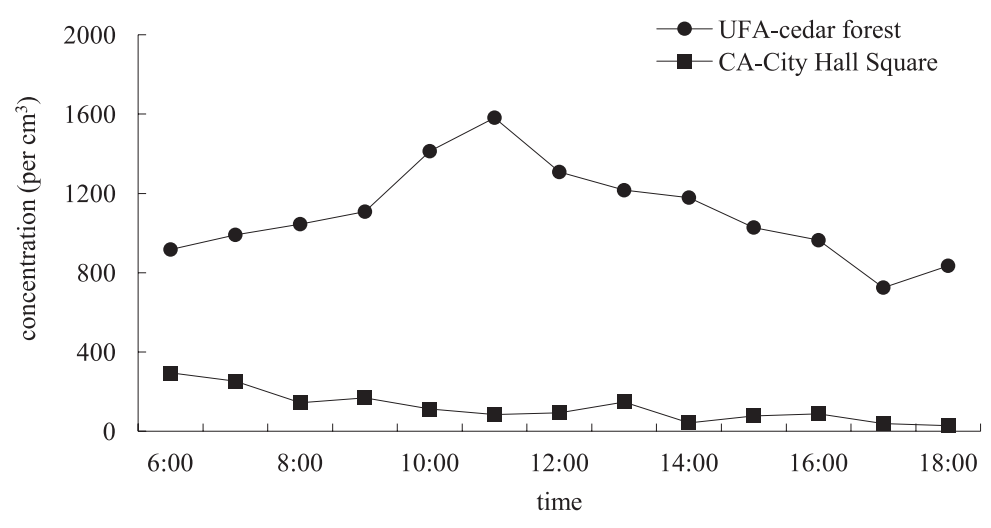

Fig. 11. Diurnal variation of negative ion concentration in cedar forest and City Hall Square.

the influence of vehicles on the concentration of anion in the air is much greater than that of people activities. At 8 a.m., 11 a.m., 14 p.m. and 18 p.m., the traffic flows increase dramatically because most people are travelling to or from work. At the same time, it is the periods when citizens dine out and go shopping, and there's a lot of foot traffic too. The maximum consumption ratio is $58.69 \%, 83.99 \%, 89.14 \%, 89.64 \%$, respectively.

Based on the comprehensive analysis of people activities, vehicle activities and mixed people and vehicle activities, it can be concluded that there is a threshold of consumption of NAIs by human body. When the concentration of negative ions decreases to a certain extent, the human body's effect tends to be 'blunt'. However, the effect of the vehicle on negative ions is basically unlimited, and can even 'eliminate' the negative ions in the air in a short time. In the experimental monitoring, on the one hand, the phenomenon of 0 value or close to 0 value appeared many times in Sanxiaokou and City Hall Square, but never in AAU. On the other hand, the concentration of negative ions in Sanxiaokou increased slightly during the period when there were relatively fewer vehicles, but it didn't show this characteristic in the City Hall Square. These experiments prove that the influence mechanism and results of personnel activities and vehicle activities on air negative ions are different, and the consumption of vehicles on air negative ions is much higher than that of simple personnel activities such as walking and cycling. Therefore, in TA, CA with large traffic flow, the consumption of NAIs by vehicles plays a dominant role, while the consumption of NAIs by human activities in these areas is relatively lower.

\section{Conclusions}

This experiment finds that the background concentration of NAIs in urban forest areas is much higher than that in other functional areas, indicating that plants are the main source of NAIs. Through the simulated natural attenuation, air anion complies

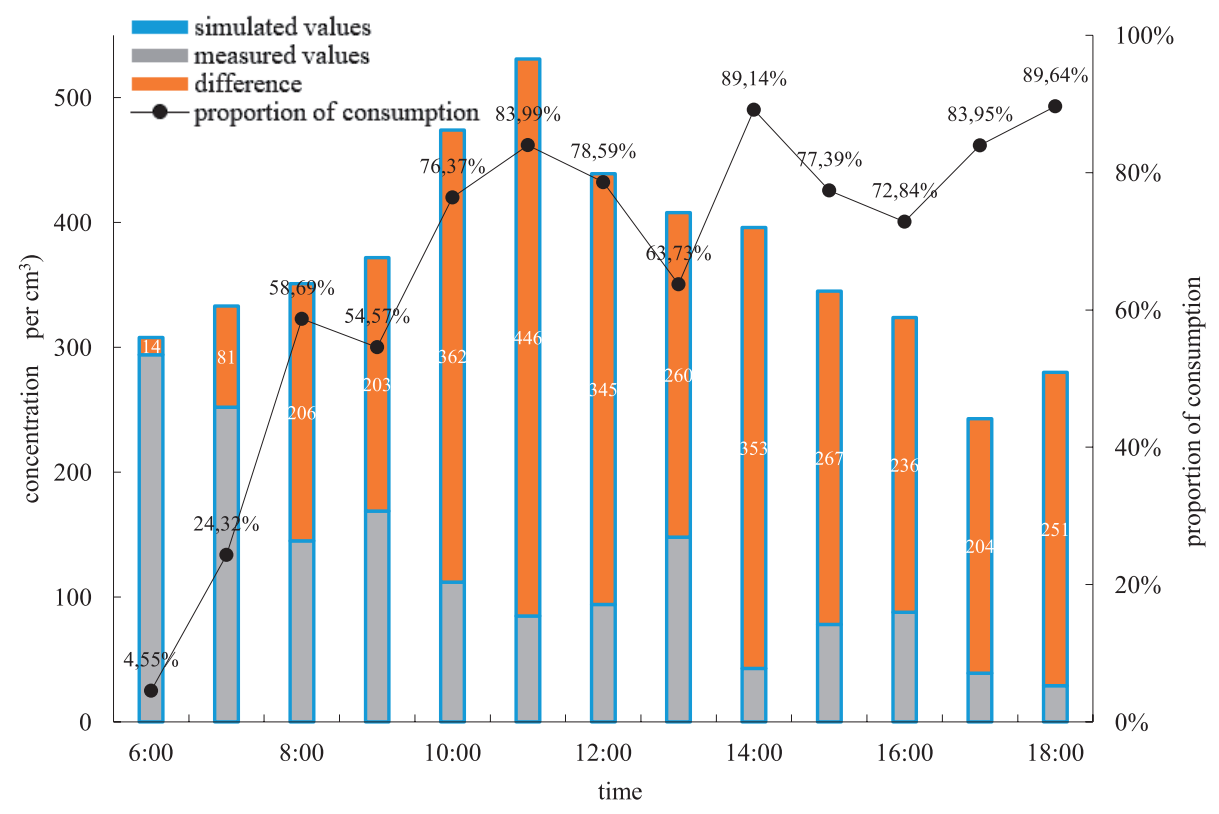

Fig. 12. The measured values, simulated values and proportion of consumption of negative air ions in the City Hall Square. 
with with this equation: $C_{(t)}=2986.6 \times e^{-0.0141 t}$. the collision probability $\alpha=0.0141$, and the half residence time is about $49.16 \mathrm{~min}$. The production or consumption of air anion environment in different functional areas of Hefei is greatly different. Among them, the urban forest area, water area, cultural and educational area and residential area produce NAIs. On the contrary, the traffic area, industrial and mining area and commercial area consume NAIs. What's more, there is a threshold value for the consumption of NAIs by personnel activities, which is generally no more than $30.00 \%$ and can reach $50.00 \%$ when the activity is intense seriously. However, no threshold value is found for vehicle activities. Based on the above results, there are two suggestions to maintain the NAIs in city. On the one hand, the vegetation area should be increased, such as the area of green space and street trees in the traffic area and commercial area. And the space of building roofs can be rationally used to promote roof gardens. On the other hand, the WA is also an important source of NAIs. Therefore, in the urban planning, the construction of imitating natural urban landscape such as man-made fountain and waterfall should be increased.

The change of NAIs is also closely related to the weather [19-20]. To further investigate the relationship between human activities and NAIs, it is also possible to study the change of negative ions under different weather conditions, such as sunny day, rainy day, cloudy day, snow day or foggy day.

\section{Acknowledgments}

This research was supported by the National Technology Support Programs (Grant No.2009BADA6B06) and the Key Project of Nature and Science Foundation in Anhui (Grant No. KJ2012Z097).

\section{Conflict of Interest}

The authors declare no conflict of interest.

\section{References}

1. ZHAO L.L., FAN X.C., HAN L., TAO H., WEI H. Impact of Urbanization on the Value of Ecosystem Services in Nanping City, China. Polish Journal of Environmental Studies, 30 (1), 965, 2021.

2. YUAN X.L., LI C.P., FANG K. Retrospect and Prospect of Research on Air Pollution in the Context of China's Urbanization. Economic Perspectives, 5, 88, 2019.

3. SHI Q., SHU H.F., ZHONG L.S., WU C.C. Research on Evaluation of the Aeroanion in Forestry Recreational Areas. Scientia Silvae Sinicae, 40 (1), 36, 2004.

4. XIA L.B. Medical Meteorology. Knowledge Press, Shanghai, China, 1984.

5. ASCHKINASS E., CASPARI W. Ueber den Einfluss dissociirender Strahlen auf organisirte Substanzen insbesondere über die bakterienschädigende Wirkung der Becquerel-Strahlen. Pflüger, Archiv für die Gesammte Physiologie des Menschen und der Thiere, 86 (11-12), 603, 1901.

6. JIANG S.Y., MA ALI, R. SRINIVASAN. Plant-based release system of negative air ions and its application on particulate matter removal. Indoor Air, 31 (2), 574, 2020.

7. VECCHIA A.D., MUCCI F., MARAZZITI D.P. 293 negative air ions in neuropsychiatry: a novel therapeutic option? European Neuropsychopharmacology, 40 (S1), 167, 2020.

8. VANA M., EHN M., PETÄJÄ T., VUOLLEKOSKI H., AALTO P., DE LEEUW G., CEBURNIS D., O'DOWD C.D., KULMALA M. Characteristic features of air-ions at Mace Head on the west coast of Ireland. Atmospheric Research, 90 (2-4), 278, 2008.

9. ZHANG F.J. Negative Air Ion Concentration of Vegetation and Water-body in Centre Park of Xiamen City. Forest Inventory and Planning, 40 (4), 19, 2015.

10. ZHANG F.J., CHEN L.Q., CHEN H.B. Distributive Characteristics of negative air ions and $\mathrm{PM}_{2.5}$ Concentration in Xiamen Botanical Garden. Acta Agricultura Jiangxi, 27 (2), 37, 2015.

11. TAO X.Y., ZHANG W.N., LU S.W., LI S.N., ZHAO N., XU X.T. Interaction between Air Negative Ions and $\mathrm{PM}_{2.5}$ Particles in Urban Forest of Beijing. Acta Agriculturae Universitatis Jiangxiensis, 42 (06), 1184,2020.

12. CHEN B.F., XIAO Y.H., WANG S.Y., WU Q.H. Changes and Relationships in Hourly Scales throughout the Year for the negative air ions and Meteorological Factors in Maofeng Mountain Forest Areas, Guangzhou. Ecology and Environmental Sciences, 29 (11), 2240, 2020.

13. TWOMEY S. Atmospheric Aerosol WANG M.X., WANG G.C. Trans. Science Press, Beijing, 1984.

14. WEI C.L., WANG J.T., JIANG Y.L, ZHANG Q.G. Air Negative Charge ion Concentration and its Relationships with Meteorological Factors in Different Ecological Functional Zones of Hefei City. Chinese Journal of Applied Ecology, 17 (11), 2158, 2006.

15. TSAO T., TSAI M., HWANG J., CHENG W., WU C., CHOU C., SU T. Health Effects of a Forest Environment on Natural Killer Cells in Humans: An Observational Pilot Study. Oncotarget, 9, 16501, 2018.

16. HANSEN M.M., JONES R., TOCCHINI K. Shinrin-Yoku (Forest bathing) and Nature Therapy: A State-of-the-art Review. International journal of environmental research and public health, 14, 851, 2017.

17. WANG X.L. Evaluation of Microclimate and Air Anion Effects in Mountainous Rural Residental Forests. Shandong Agricultural University, 2011.

18. WU C.C., ZHENG Q.M., ZHONG L.S. A Study of the Aero-anion Concentration in Forest Recreation Area. Scientia Silvae Sinicae, 5, 75-81, 2001.

19. WANG H., WANG B., NIU X., SONG Q.F., LI M.W., LUO Y.Y., LIANG L.D., DU P.F., PENG W. Study on the change of negative air ion concentration and its influencing factors at different spatio-temporal scales. Global Ecology and Conservation, 23, e01008, 2020.

20. MIAO S., ZHANG X.Y., HAN Y.J., SUN W., LIU C.J., YIN S. Random Forest Algorithm for the Relationship between Negative Air Ions and Environmental Factors in an Urban Park. Atmosphere, 9, 463, 2018. 
